\title{
Epidemiological Approach to the Use of Psychotropic Medications at Moulay El Hassan Hospital, in the Gharb Region of Morocco
}

\author{
Zahra Dakir ${ }^{1}$, Ahmed Ahami' ${ }^{1}$, Sanae Sadek ${ }^{2}$, Samira Mouden1, Asmae Belala², \\ Fatima Benel Harkati², Khalid Bouchikh ${ }^{3}$
}

\author{
${ }^{1}$ Equip of Clinical and Cognitive Neuroscience and Health, Department of Biology, Faculty of Science, Ibn Tofail University, \\ Kenitra, Morocco \\ ${ }^{2}$ Department of Biology, Faculty of Science, Ibn Tofail University, Kenitra, Morocco \\ ${ }^{3}$ Moulay El Hassan Health Center, Psychiatry Department, Kenitra, Morocco \\ Email: dakirzahra@hotmail.com, dakirzahra@yahoo.fr
}

How to cite this paper: Dakir, Z., Ahami, A., Sadek, S., Mouden, S., Belala, A., Harkati, F.B. and Bouchikh, K. (2017) Epidemiological Approach to the Use of Psychotropic Medications at Moulay El Hassan Hospital, in the Gharb Region of Morocco. Neuroscience \& Medicine, 8, 9-23.

https://doi.org/10.4236/nm.2017.82002

Received: January 12, 2017

Accepted: June 16, 2017

Published: June 19, 2017

Copyright () 2017 by authors and Scientific Research Publishing Inc. This work is licensed under the Creative Commons Attribution International License (CC BY 4.0).

http://creativecommons.org/licenses/by/4.0/

\begin{abstract}
The use of psychotropic drugs is important in Morocco related to the large amount of sufferers by psychiatric disorders, according to a survey of the Moroccan Ministry of Health (2010). A prevalence of $26.5 \%$ of depressive disorders, and $9 \%$ for generalized anxiety disorder, and $5.6 \%$ of psychotic disorders was recorded within population, hence the importance to describe the use and assess the prevalence of psychotropic and socio-economic factors was associated with their use. Our research is a retrospective study, carried out between February 2010-December 2013, holding a sample of 5618 patients aged between 1 and 90 years old. The study is concerned with drawing social and clinical data from patients' records. The different classes of psychotropic drugs prescribed to patients in the psychiatric department Moulay El Hassan Hospital, vary between antidepressants (36\%), antipsychotics (32\%), anxiolytics (10\%), anti-epileptics (9\%), the class of diverse "sulpiride" (7\%), anti-parkinsonian (6\%), and hypnotics were prescribed in rare cases. The relationship between socio-economic factors and the take of a psychotropic treatment was very strong in Morocco. In contrast, the patients support showed by close families and the health care staff remain a challenge for Moroccan population.
\end{abstract}

\section{Keywords}

Psychotic Disorders, Psychotropic, Socio-Economic Factors, Morocco

\section{Introduction}

A psychotropic drug is defined in The Elaborate Terminological Dictionary at 
the Office of the French Language as: "A chemical substance of natural or artificial origin, which is likely to modify mental activity and whose main action gets exerted at central nervous system, and indirectly, but regularly on the psyche." This definition is accompanied with the following note: "Psychotropic drugs cover a wide variety of agents including those that modify the behavior by direct or indirect action on the central nervous system or by peripheral action." We also talk about psychotropic drugs, as those "used primarily for their effects on consciousness, mood, and perception of internal and external environments" [1].

In Morocco, a survey conducted by the CNOPS (National Fund for social Prediction and Security bodies) shows a slight female predominance. Psychotropic drugs were prescribed in half of the cases between 40 and 60 years old. Generalists are the leading prescribers with $(27.2 \%)$, followed by psychiatrists (19\%). Anxiolytics are the most frequently prescribed (44.9\%) of psychotropic drugs, followed by antipsychotics (25.2\%) and antidepressants (18.7\%), and finally hypnotics with (3\%) of cases. Women consumed more anxiolytics and antidepressants than men [2]. Moreover, psychotropics have witnessed a considerable evolution during recent years. They have got to approach the neurobiological and psychopharmacology slopes of mental illness. Throughout the years, research has led to improve modes of action with more specificity, and better tolerance. Hence the emergence of new generations of psychotropic drugs has been given birth. However, medically speaking, prescribing psychotropic is not going without causing some problems in terms of indication, dosage or treatment time duration [3].

Our study's objective is to highlight the different classes of psychotropic drugs prescribed by psychiatrists, and the factors influencing the use or consumption of psychotropic drugs in the population.

\section{Method}

Our research is a retrospective study, conducted between February 2010 up to December 2013. About 5618 cases of study, aged between 1 and 90 years old, living in The Gharb-Cherarda Beni Hssen Region and consultant at The Psychiatric Health Center at "Moulay El Hassan Hospital". Mental Health Department, located in the city of Kenitra (North west of Morocco). The study is concerned with raising social and clinical data from patients' records. These forms were filled out by psychiatrists. The variables used in this research were: sex, age, origin, household size, Social rank among siblings, parents, marital status, educational level, occupation, and income.

Psychotropic medicines prescribed to patients were noted from the records of patients who make use of psychotropic drugs delivered in each consultation.

The list of psychotropic drugs has been enumerated based on the International Classification of (Delay and Deniker) as well as (Vidal, 2012). However, it should be revealed that some products may be prescribed for their muscle relaxant effects such as: vitamins, Oligo-elements such as "Magnesium" and Anti- 
histamines, have not been considered as psychotropic drugs in our work except the active ingredient "Sulpiride" which is classified in the diverse family which was taken into account, thanks to its psychostimulant effect.

Statistical analysis was based on a prevalence calculation of the use of psychotropic drugs in the population, and secondly, prevalence calculation of socioeconomic variables.

\section{Results}

\subsection{Presentation of Psychotropic Drugs Classes}

The different categories of psychotropic drugs, prescribed to patients in the psychiatric department at Moulay El Hassan Hospital in Kenitra city vary between antidepressants (36\%), neuroleptic (32\%), whereas anxiolytics represent (10\%), while anti-epileptics were prescribed with an average rate of $(9 \%)$. In contrast, the diverse class were prescribed by $(7 \%)$ of cases, while anti-parkinsonians were by an average rate of (6\%) and hypnotics were prescribed in rare cases, in a negligible prevalence (Figure 1).

\subsection{Distribution of Psychotropic Consumption according to Age Categories “[0, 20[; [20, 40[; [40, 60[; [60, 80[; [80, 100[" The Age Categories per Year}

The use of neuroleptics was higher among the highest age categories between (80 - 100) years old. Prevalence were at an average rate of (85.45\%) and also were higher in young patients $(20-40)$ years, in which the prevalence were $(53.22 \%)$, and tend to decrease among the remaining age groups between $(60-80)$ years, were by $(50.92 \%)$, for ages between $(0-20)$ years, were by $(49.33 \%)$, and regarding the age categories between $(40-60)$ years, the prevalence were by $(46.79 \%)$. However, the consumption of antidepressants was higher in patients aged between $(40-60)$ years, the prevalence were by $(23.02 \%)$ and by $(21.73 \%)$ for pa-

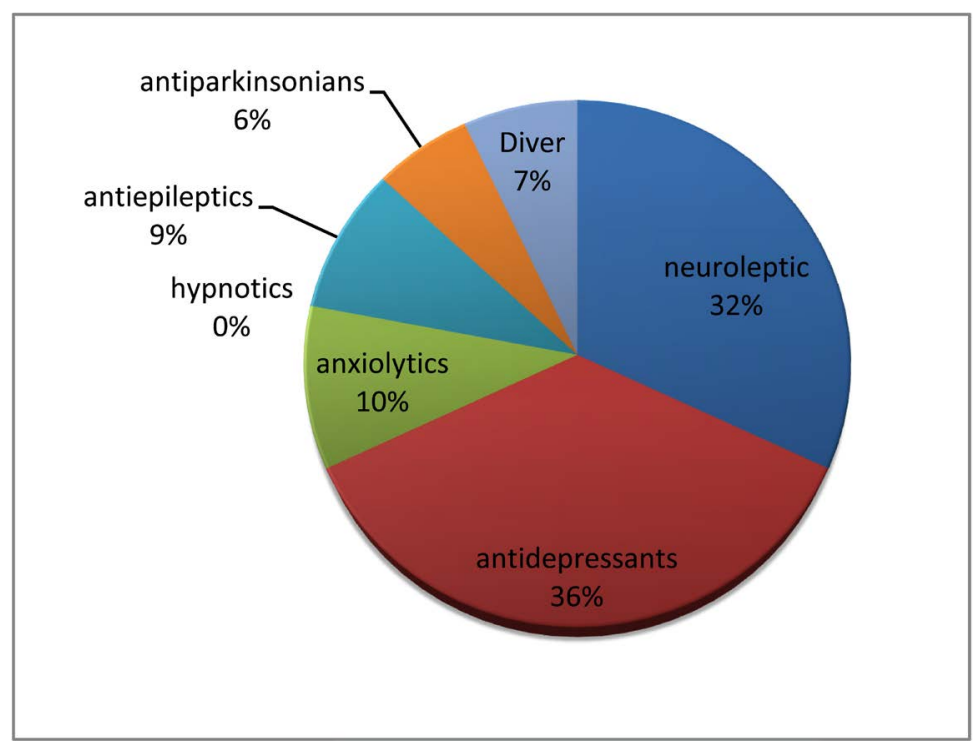

Figure 1. Presentation of psychotropic drugs classes. 
tients age category between $(60-80)$ years, but still the prevalence were by $(19.84 \%)$ and by (13.86\%) respectively for age categories between (20 - 40) years old and $(0-20)$ years old, and only $(7.00 \%)$ for the highest age categories between $(80-100)$ years. Moreover, taking anxiolytics by patients age groups between $(40-60)$ years, were by $(14.34 \%)$ and $(13.26 \%)$ with patients age groups between $(60-80)$ years, and (11.54\%) for those age categories between $(20-40)$ years, and $(7.08 \%)$ among the detected cases whose ages were between $(0-20)$ years, there is a very low prevalence of $(4.85 \%)$ among those the highest age groups $(80-100)$ years. While the consumption of hypnotics or sedatives were very lower, whatever the age category does not exceed $(0.16 \%)$ for patients age categories between $(40-60)$ years but, these were neglected for the remaining patients. While antiepileptic were marked with a high prevalence $(24.85 \%)$ among the youngest patients $(0-20)$ years. On the other hand the consumption of antiepileptic was still very lower in the other patients. Prevalence was respectively $(4.60 \%)(7.09 \%)(5.89 \%)$ and $(0.54 \%)$ for the age groups $(20-40)$ years, $(40$ - 60) years, $(60$ - 80) years, and $(80-100)$ years. Indeed, taking anti-Parkinsonian for patients of age between $(20-40)$ years, were $(6.94 \%)$, and $(4.56 \%)$ among those whose ages were between (40 - 60) years, and (4.05\%) with patients age groups between $(60-80)$ years, and (3.59\%) among youth $(0-20)$ years, and low $(0.54 \%)$ the oldest patients $(80-100)$ years. However, the consumption of drugs of various family was $(4.14 \%)$ in patients aged $(60-80)$ years, and $(4.03 \%)$ among those whose age range was between $(40-60)$ years, and $(3.85 \%)$ for patients $(20-40)$ years, and $(1.62 \%)$ older $(80-100)$ years, and $(1.28 \%)$ patients the youngest $(0-20)$ years. The results have shown that there is a highly significant correlation between age and the consumption of psychotropic drugs, at $\mathrm{p}<$ $0.001 \mathrm{r}=0.95$ (Figure 2).

\subsection{Distribution of Psychotropic Consumption according to Socio-Economic}

Men frequently use neuroleptics (62.05\%) while women use them by an average rate of (37.95\%). Accordingly, women use antidepressants (66.65\%) more than

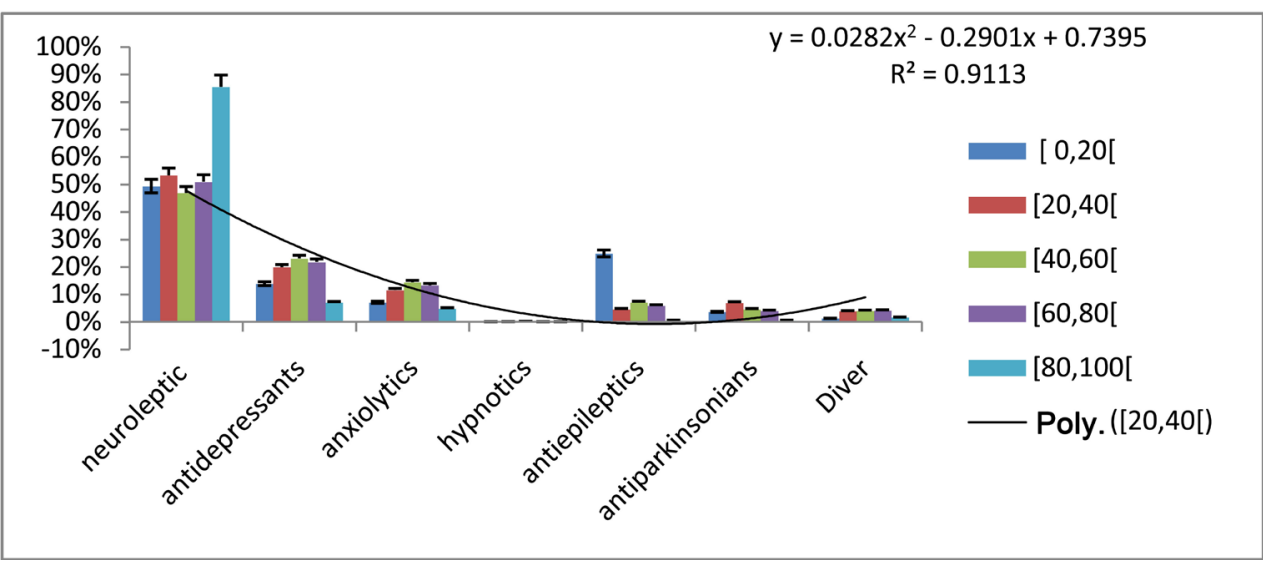

Figure 2. Distribution of psychotropic consumption according to age categories. " $[0,20[;[20,40[$; $[40,60[;[60,80[;[80,100["$ The age categories per year. 
men (33.35\%). However, the consumption of anxiolytics by women was higher $(66.35 \%)$ than men $(33.65 \%)$. The use of hypnotics was by anerage rate of $(57.14 \%)$ by women, and $(42.86 \%)$ by men. Moreover, the take of anti-epileptics was generally differed by a slight variation between men $(55.75 \%)$ and women $(44.25 \%)$. While the consumption of anti-Parkinson tends to increase among men $(63.97 \%)$ compared to women $(36.03 \%)$

It was noticed that women $(68.06 \%)$ were higher consumers of diverse drugs than males (31.94\%). The results have shown that there is a highly significant correlation between sex gender and consumption of psychotropic drugs, at $\mathrm{p}<$ 0.0001 .

The prevalence of neuroleptic consumptive use among patients living in urban areas was $(54.96 \%)$. Whereas with patients living in rural areas, the prevalence was about (40.98\%). In fact, among the temporary users were about (4.06\%). Moreover, the prevalence of antidepressant users was higher among patients living in urban areas, followed by patients living in rural areas. Prevalence were respectively by $(71.88 \%)$ and $(24.52 \%)$. On the other hand, Prevalence among momentary-user patients was lower than (3.61\%). However, the take of anxiolytics by patients living in rural areas and those living in urban areas was respectively at the rate of $(47.56 \%)$ and $(43.97 \%)$. But, the prevalence was lower with momentary-user patients at the rate of $(8.47 \%)$. In contrast, the prevalence of consumption of hypnotics was much higher with patients living in the urban area at the rate of $(100 \%)$, whereas the prevalence of their use by patients living in rural areas, and by temporary-user patients was negligible. While the prevalence of consumption of anti-epileptics with patients living in rural areas, were at the rate of $(54.89 \%)$, and were at the rate of $(41.73 \%)$ with patients living in urban areas. While with momentary-user patients were lower at the rate of (3.38\%). In fact the prevalence of the take of anti-parkinsonian with patients living in the urban area were higher (56.28\%), and tends to decrease among those living in rural areas (41.62\%) and among momentary-user patients (2.09\%). However, the prevalence of drug use of diverse family with patients living in rural areas was at the rate of (58.79\%), and with patients living in urban areas was at the rate of $(35.43 \%)$. whereas with temporary-user patients were lower at the rate of $(5.78 \%)$. The results have shown that there is a significant correlation between the origin and consumption of psychotropic drugs, at $\mathrm{p}<$ 0.01 .

Neuroleptics consumption with patients classified in the $2^{\text {nd }}$ and $3^{\text {rd }}$ position among siblings, is defined by higher prevalence $(33.80 \%)$ and $(33.27 \%)$. While the prevalence of neuroleptics taken by patients classified into the first row by a rate of $(26.78 \%)$, and for patients classified in the fourth row were at a rate of $(6.15 \%)$. Moreover, the prevalence of antidepressant users were higher among patients classified on the $2^{\text {nd }}$ and $3^{\text {rd }}$ row, and were at the rate of $(34.51 \%)$ and (33.38\%), and (25.49\%) with patients classified in the first row, and $(6.62 \%)$ among those classified in the $4^{\text {th }}$ rate. However taking anxiolytics with patients classified in the $2^{\text {nd }}$ and $3^{\text {rd }}$ row were respectively at the rate of $(33.76 \%)$ and 
(32.05\%), and (27.99\%) with patients classified on the $1^{\text {st }}$ row, and $(6.20 \%)$ with those classified in the $4^{\text {th }}$ rate. While the consumption of hypnotics were (40.00\%) higher than with patients in the second or third row, and $(20.00 \%)$ with patients classified in the first rate, and negligible with those classified in the $4^{\text {th }}$ position. The consumption of antiepileptics was marked with a high prevalence for patients classified into the second row were $(40.90 \%)$. On the other hand were $(29.01 \%)$ in patients classified as $3^{\text {rd }}$ row and $(24.85 \%)$ among those classified in the first place, and (5.23\%) patients in the fourth row. In fact, taking anti-parkinsonian drugs with patients classified as $1^{\text {st }}$ row were high $(40.14 \%)$, and in patients classified in $2^{\text {nd }}$ and $3^{\text {rd }}$ row were respectively $(27.60 \%)$ and $(27.06 \%)$, but were lower with $(5.20 \%)$ in patients classified in $4^{\text {th }}$ place. However, the consumption of drugs of diverse family was at the rate of $(38.96 \%)$ with patients classified in the $2^{\text {nd }}$ row, and (30.72\%) among those classified in the first rate, eventually were at the rate of $(22.49 \%)$ with patients classified in the third row, and do not exceed (7.83\%) with patients classified in the $4^{\text {th }}$ row. The results have shown that there is a significant correlation between sibling's rank and psychotropic drugs consumption, at $\mathrm{p}<0.01$.

The prevalence of neuroleptics use with patients in large households was at the rate of $(36.00 \%)$. Whereas with patients in average household was at the rate of (34.45\%), with those of small households was at the rate of (29.55\%). Moreover, the prevalence of antidepressant were respectively higher among average as well as small households was at the rate of (36.99\%) and (35.04\%), but it was lower among patients living in large households (27.97\%). However, the take of anxiolytics by patients of respectively average as well as small households was at the rate of (37.25\%) and (36.82\%), but it was lower among patients living in large households at the rate of $(25.93 \%)$. But the consumption of hypnotics was much higher with patients living in small household (91.11\%), while the prevalence of their use with patients of average households was much weaker at the rate of $(8.89 \%)$, but was negligible with patients in large households. The prevalence of consumption with patients of average households was at the rate of $(37.36 \%)$ and was at the rate of (31.32\%) higher than with patients living in small households or those in large families. In fact, the take of anti-parkinsonian by patients of average household was higher at the rate of $(67.43 \%)$ and tends to decrease respectively among those in large households as well as small households at the rate of $(18.89 \%)$ and (13.67\%). However, the consumption of drugs of diverse families with patients living respectively in average as well as small households was at the rate of $(36.29 \%)$ and $(33.28 \%)$, whereas with patients of large households was at the rate of $(30.43 \%)$. The results have shown that there is no correlation between household size and consumption of psychotropic drugs.

Single patients use neuroleptics at a higher frequency. Prevalence were at the rate of $(54.53 \%)$, while the prevalence among married patients was at the rate of (37.55\%), and tends to decrease respectively with divorced patients and widows at the rate of $(4.71 \%)$ and $(3.21 \%)$. In contrast, the consumption of antidepressants was higher among married patients. The prevalence were at the rate of 
$(59.32 \%)$, and single patients were at the rate of $(29.68 \%)$, but they were respectively lower for widows and divorced patients at the rate of (5.67\%) and (5.33\%). While the take of anxiolytics by married patients was higher at the rate of (59.40\%), whereas their use with single patients was at the rate of $(27.78 \%)$. In fact, the prevalence were respectively lower with widows and divorced patients at the rate of $(6.62 \%)$ and $(6.20 \%)$. However, the prevalence of consumption of hypnotics was much higher among married patients at the rate of $(80.00 \%)$, whereas among widows and widows patients were at the rate of $(20.00 \%)$, whereas that was insignificant among single and divorced patients. In contrast, the prevalence of consumption of antiepileptic drugs with single patients was much higher at the rate of $(63.59 \%)$, while among married patients was at the rate of $(30.21 \%)$, and were respectively lower regarding widows and divorced patients at the rate of $(3.29 \%)$ and $(2.91 \%)$. Furthermore, the take of anti-parkinsonian by single patients was far higher by $(92.44 \%)$ but it was lower among married patients as well as divorced and widows. The prevalence was respectively at the rate of $(6.20 \%),(0.77 \%)$ and $(0.59 \%)$. However, the consumption of drugs of diverse family was higher among married patients. The prevalence was at the rate of $(61.20 \%)$, and single patients were at the rate of $(27.76 \%)$. On the other hand, they were respectively lower concerning divorced and widows patients with an amount of $(6.02 \%)$ and $(5.02 \%)$. The results have shown that there is a highly significant correlation between marital status and the consumption of psychotropic drugs, at $\mathrm{p}<0.0001$.

Patients whose fathers are still alive consume more neuroleptics than those whose fathers are dead. In fact, the prevalence of their consumption was higher with patients with living fathers at a rate of $(60.78 \%)$ and lower among those with died fathers at a rate of (39.22\%). Regarding the consumption of antidepressants, prevalence were higher in both cases and were respectively at the rate of $(55.59 \%)$ and $(44.41 \%)$ regarding patients with living fathers and fathers who died. In contrast, the prevalence of consumption of anxiolytics was at the rate of (56.41\%) with patients whose fathers are alive, and by $(43.59 \%)$ among patients whose fathers are dead. Moreover, the prevalence of consumption of hypnotics was too higher with patients with dead fathers by $(80.00 \%)$, whereas patients with living fathers were by $(20.00 \%)$. However, the prevalence of consumption of antiepileptic drugs by patients with living fathers were very higher at a rate of $(65.78 \%)$, but it was lower in patients whose fathers are dead at a rate of (34.22\%). However, the take of anti-parkinsonian by patients with living fathers were at the rate of $(60.48 \%)$, and those with dead fathers were at the rate of (39.52\%). While the consumption of drugs of diverse family was also much higher in patients with living fathers (53.51\%) than those with dead fathers (46.49\%).The results have shown that there is a significant correlation between the presence of the father and the consumption of psychotropic drugs, at $\mathrm{p}<$ 0.01 .

The prevalence of the use of neuroleptics was up in patients with living mothers at a rate of (76.60\%) and lower in those whose mothers died (23.40\%). In 
contrast, the prevalence of consumption of antidepressants in patients with living mothers was much higher at a rate of $(89.19 \%)$, while it was lower in those whose mothers died by $(10.81 \%)$. Yet, the prevalence of consumption of anxiolytics was at the rate of (71.26\%) among patients with living mothers and $(28.74 \%)$ in those whose mothers died. However, the prevalence of consumption of hypnotics was higher among patients with living mothers by a rate of $(60.00 \%)$, while those whose mothers died the prevalence were at the rate of (40.00\%).

Moreover, the prevalence of consumption of anti-épileptics among patients with living mothers was very much higher by $(80.66 \%)$, but it was lower among those whose mothers died by a different rate of $(19.34 \%)$. In fact, the take of anti-parkinsonian by patients with living mothers was very higher at a rate of (76.20\%) and was lower among those whose mothers died by a rate of $(23.80 \%)$. Still, the prevalence of drug use typed as diverse family was higher among patients with living mothers at a rate of $(71.40 \%)$, and it was lower in those whose mothers died by a rate of $(28.60 \%)$. The results have shown that there is a significant correlation between the presence of the mother and the consumption of psychotropic drugs, at $\mathrm{p}<0.01$ (Table 1 ).

Table 1. Distribution of psychotropic consumption according to Socio-economic Factors: Sex; Origin; Sibling Rank; Household Size; Marital Status; Father Situation; Mother Situation $(\mathrm{n}=5618)$.

\begin{tabular}{|c|c|c|c|c|c|c|c|c|}
\hline & & Neuroleptic \% & Antidepr \% & Anxiolytic \% & Hypnotic \% & Antiepileptic \% & Antipark \% & Diver \% \\
\hline \multirow{2}{*}{ Sex } & Women & 37.95 & 66.65 & 66.35 & 57.14 & 44.25 & 36.03 & 68.06 \\
\hline & Men & 62.05 & 33.35 & 33.65 & 42.86 & 55.75 & 63.97 & 31.94 \\
\hline \multirow{3}{*}{ Origin } & Urban & 54.96 & 71.88 & 43.97 & 100 & 41.73 & 56.28 & 35.43 \\
\hline & Rural & 40.98 & 24.52 & 47.56 & 0 & 54.89 & 41.62 & 58.79 \\
\hline & Momentary-user patients & 4.06 & 3.61 & 8.47 & 0 & 3.38 & 2.09 & 5.78 \\
\hline \multirow{4}{*}{ Sibling Rank } & $1^{\text {st }}$ row & 26.78 & 25.49 & 27.99 & 20 & 24.85 & 40.14 & 30.72 \\
\hline & $2^{\text {nd }}$ row & 33.8 & 34.51 & 33.76 & 40 & 40.90 & 27.60 & 38.96 \\
\hline & $3^{\text {rd }}$ row & 33.27 & 33.38 & 32.05 & 40 & 29.01 & 27.06 & 22.49 \\
\hline & $4^{\text {th }}$ row & 6.15 & 6.62 & 6.20 & 0 & 5.23 & 5.2 & 7.83 \\
\hline \multirow{3}{*}{ Household Size } & Small household & 29.55 & 35.04 & 36.82 & 91.11 & 31.32 & 13.67 & 33.28 \\
\hline & Average household & 34.45 & 36.99 & 37.25 & 8.89 & 37.36 & 67.43 & 36.29 \\
\hline & Big household & 36.00 & 27.97 & 25.93 & 0 & 31.32 & 18.89 & 30.43 \\
\hline \multirow{4}{*}{ Marital Status } & Married & 37.55 & 59.32 & 59.40 & 80 & 30.21 & 6.20 & 61.2 \\
\hline & Single & 54.53 & 29.68 & 27.78 & 0 & 63.59 & 92.44 & 27.76 \\
\hline & Divorced & 4.71 & 5.33 & 6.20 & 0 & 2.91 & 0.77 & 6.02 \\
\hline & Widow & 3.21 & 5.67 & 6.62 & 20 & 3.29 & 0.59 & 5.02 \\
\hline \multirow{2}{*}{ Father Situation } & Alive & 60.78 & 55.59 & 56.41 & 20 & 65.78 & 60.48 & 53.51 \\
\hline & Dead & 39.22 & 44.41 & 43.59 & 80 & 34.22 & 39.52 & 46.49 \\
\hline \multirow{2}{*}{$\begin{array}{l}\text { Mother } \\
\text { Situation }\end{array}$} & Alive & 76.60 & 89.19 & 71.26 & 60 & 80.66 & 76.20 & 71.4 \\
\hline & Dead & 23.40 & 10.81 & 28.74 & 40 & 19.34 & 23.80 & 28.6 \\
\hline
\end{tabular}




\subsection{Distribution of Psychotropic Consumption according to Level of Education}

At this study, we notice that the prevalence of neuroleptics use by illiterate patients were at the rate of (47.38\%), whereas by those who have a primary or secondary level of education, the prevalence were at the rate of $(44.03 \%)$, but among patients with higher level of education the prevalence were lower at the rate of $(8.59 \%)$. In contrast, the consumption of antidepressants were higher with illiterate patients in that the prevalence were at the rate of $(58.38 \%)$, and those with a primary or secondary level of education the prevalence were at the rate of (34.72\%), but they were lower with patients with higher level of education by a rate of (6.90\%). The prevalence of anxiolytics consumption was much higher in illiterate patients and those with a primary or secondary level of education. The prevalence was respectively at a rate of $(57.37 \%)$ and (36.32\%), while the proportion with patients with higher level of education were lower than (6.30\%). Moreover, the prevalence of consumption of hypnotics was far higher with patients who have a primary or secondary level of education by a rate of $(80.00 \%)$, whereas illiterate patients were at a rate of $(20.00 \%)$ yet, it was not among patients with higher level of education. However, the prevalence of consumption of antiepileptic drugs among illiterate patients were much higher than (51.21\%), and (43.82\%) among those with a primary or secondary level of education. by contrast, they were lower with patients with a higher educational level at a rate of (4.97\%). In effect, the take of anti-parkinsonian by patients with primary or secondary level of education and illiterate patients were higher in that prevalence were respectively at the rate of $(47.60 \%)$ and $(43.89 \%)$, whereas with patients with higher level of education the prevalence was lower than (8.52\%). Still, the consumption of drugs classified as diverse family was higher with patients with a primary or secondary level of education in that the prevalence were at the rate of (65.61\%), whereas with illiterate patients were at a rate of $(29.72 \%)$, but for patients with a higher educational level, the prevalence was lower at the rate of (4.67\%). The results have shown that there is a highly significant correlation between educational level and consumption of psychotropic drugs at $\mathrm{p}<0.001, \mathrm{r}=0.47$ (Figure 3 ).

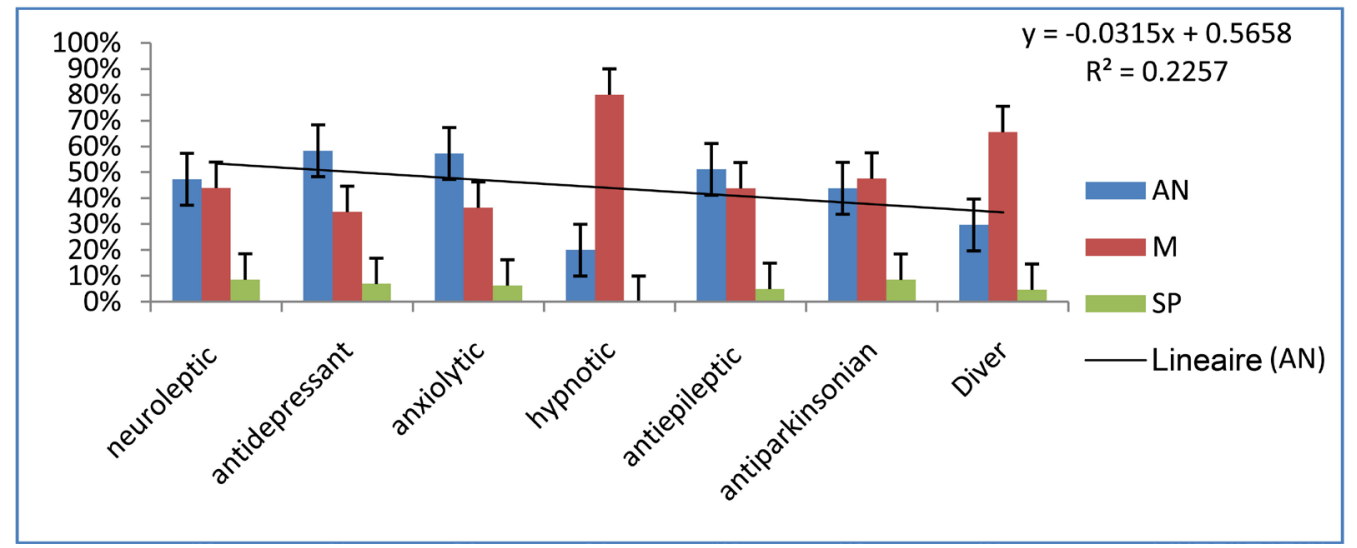

AN: Illiterate; M: medium level (primary and secondary); SP: undergraduate and postgraduate level.

Figure 3. Distribution of psychotropic consumption according to level of education. 


\subsection{Distribution of Psychotropic Consumption according to the Occupation}

At this study, we notice that the prevalence of neuroleptics use was higher among inactive or unemployed patients at a rate of (79.20\%), while in active patients were at a rate of (19.96\%) and among those who were retired by $(0.84 \%)$. In contrast, the prevalence of antidepressant use was higher among inactive or unemployed patients at a rate of (81.20\%), and tends to decrease among active patients and retired in which the prevalence were respectively at the rate of $(17.77 \%)$ and $(1.03 \%)$. In contrast, the prevalence of consumption of anxiolytics was by $(80.34 \%)$ in inactive or unemployed patients whereas among active it was at the rate of $(18.70 \%)$, and among retired patients was at the rate of $(0.96 \%)$.

Moreover, the prevalence of consumption of hypnotics was higher among active patients at a rate of $(60.00 \%)$; that is lower by $(20.00 \%)$ than among patients with inactive or retired patients. However, the prevalence of use of ant-iepileptic drugs was higher in inactive or unemployed patients at a rate of $(85.66 \%)$, whereas in active patients it was at the rate of (14.10\%). Patients and pensioners were at a rate of $(0.23 \%)$. In fact, the prevalence of anti-parkinsonions consumption was at the rate of $(78.17 \%)$ in inactive or unemployed patients; whereas, in active patients was by $(21.18 \%)$ and retired patients was by $(0.66 \%)$. However, the prevalence of drug use typed as diverse family was higher among inactive or unemployed patients by a rate of $(79.43 \%)$; whereas, in active patients was at the rate of (19.57\%), and retired patients was lower by (1.00\%). The results have shown that there is a highly significant correlation between the occupation and the consumption of psychotropic drugs, at $\mathrm{p}<0.001, \mathrm{r}=0.10$ (Figure 4).

\subsection{Distribution of Psychotropic Consumption according to the Income}

The prevalence of neuroleptics use was higher among patients who have no income. The average rate was (79.27\%), whereas in those with a regular income,

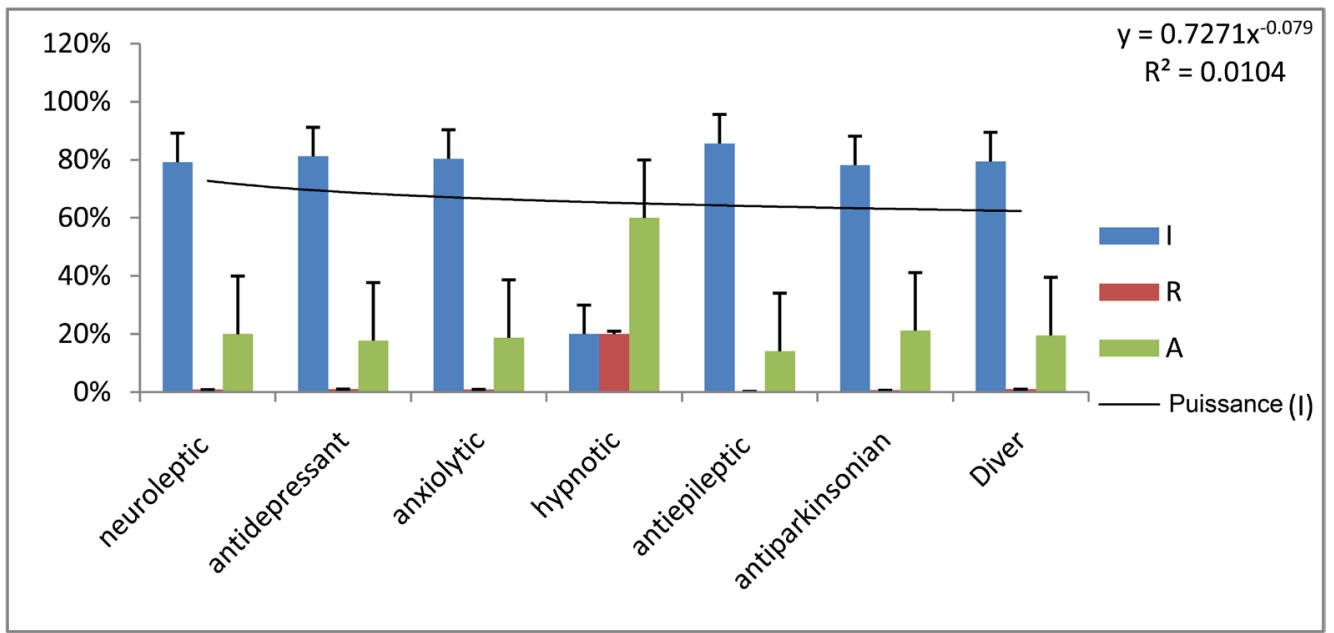

A: Active, R: Retired, I: inactive or unemployed.

Figure 4. Distribution of psychotropic consumption according to the occupation. 
the rate was lower than (20.73\%). Yet, the prevalence of antidepressant use was higher in patients who do not have income $(81.14 \%)$, and was at a rate of (18.86\%) among patients with a regular income. In fact, the prevalence of consumption of anxiolytics was at the rate of $(80.13 \%)$ in patients who have no income, while in those with a regular income was at an average rate of (19.87\%). Moreover, the prevalence of consumption of hypnotics was higher among patients with a steady income at an average rate of (80.00\%). By contrast, it was lower in patients who have no income at an average rate of (20.00\%). Despite the fact, the prevalence of the use of antiepileptic drugs was comparatively much higher among patients who have no income at an average rate of (86.94\%); whereas their use in patients with a regular income was lower at a rate of (13.06\%). Regarding the consumption of Anti-Parkinsonism, the prevalence was at the rate of (78.38\%) among patients who have no income whereas in those with a steady income, it was about (21.62\%). In contrast, the prevalence of drug use of the diverse families was higher in patients who do not have income at an average rate of $(79.26 \%)$ comparatively with those with a regular income in which the prevalence was lower at a rate of $(20.74 \%)$. The results have shown that there is a highly significant correlation between income and consumption of psychotropic drugs, at $\mathrm{p}<0.001, \mathrm{r}=0.4$ (Figure 5).

\section{Discussion}

The analysis of these data shows that the use of psychotropic drugs was comparatively higher among women than men. This difference between sex gender is also found in all epidemiological studies in France [5] [6], as well as in other countries [3] [7] [8]. These results can be accounted for by the fact that the conditions in which psychotropic treatments are prescribed are more common among women (mood disorders and anxiety disorders) treated with antidepressants, anxiolytics, and by drugs of diverse family "sulpiride" [9] [10] [11] [12] than men (disorders and Schizophrenia psychotic disorders) [13] [14], who were treated by neuroleptics, antiepileptics associated with antiparkinsonian so as to

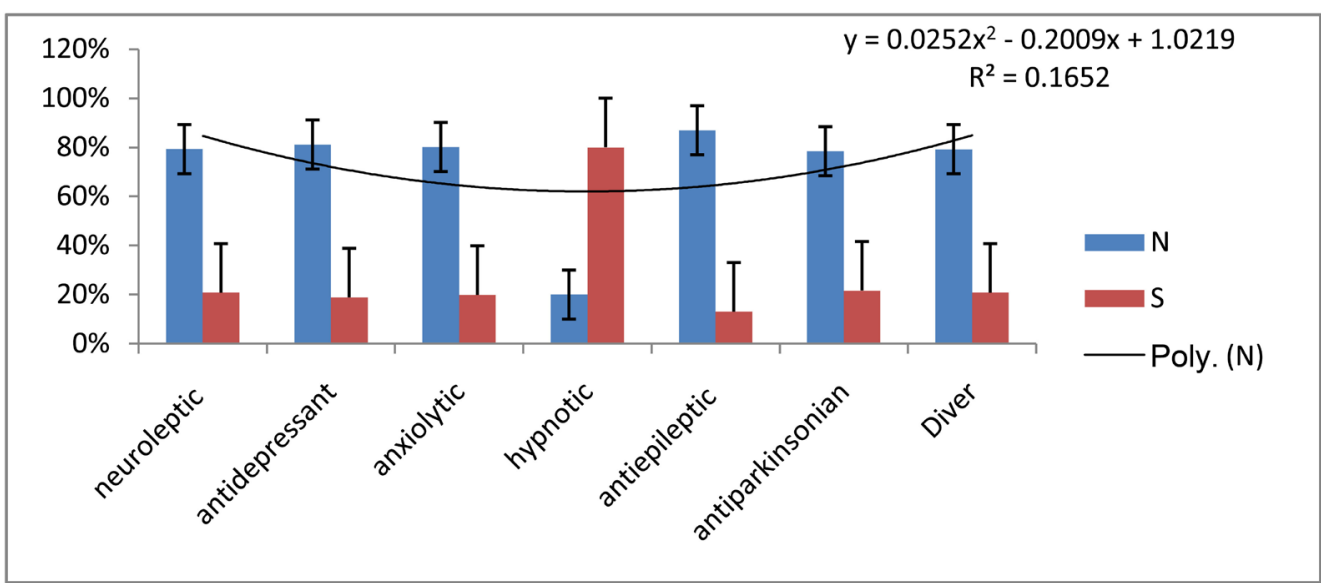

$\mathrm{N}$ : No income; S: Steady income (regular).

Figure 5. Distribution of psychotropic consumption according to the income. 
correct some negative effects which were caused mainly by taking these neuroleptics [14] [15] [16].

The use of psychotropic drugs was recognized in all age groups [17] [18] [19]. However, the take of neuroleptics, antidepressants and anxiolytics was highly important in the older age groups. This result is consistent with several international studies [20] [21]. The latter could be explained by the fact which stated that the use of psychotropic seems to increase with age [19] [22] [23].

Within this same population we notice a higher consumption of psychotropic drugs among individuals living either in urban or rural areas (all classes of psychotropic drugs), living alone or with families; either small, medium, or large household with insufficient social support [24] [25]. However, these socio-economic factors are related to the presence of psychological disorders, requiring care, support and treatment with psychotropic drugs. These results are quite consistent with the results achieved by [25] [26] [27].

We noticed a predominance of hypnotics, neuroleptics, antidepressants and anxiolytics consumption among those classified in the $2^{\text {nd }}$, or $3^{\text {rd }}$ rank in the siblings. However, the majority of patients have one or both parents dead and living in hard socio-economic conditions. This result is consistent with several international studies [28] [29] [30]. Furthermore, we discern a higher consumption of psychotropic drugs among single individuals and married, and among those divorced or widowers. In fact, in the same population, we notice a higher consumption of psychotropic drugs among illiterate individuals, and those with a primary or secondary level of education. While the use of psychotropic remains lower among individuals with higher level of education. These results can be explained by the fact of being in a family whose socio-economic situation is difficult, living alone or with lack of social support from the surrounding social background, and to be unemployed, inactive and without a single income. However, these socio-economic factors were strongly associated with the presence of psychological disorders, and need to be supported by psychological treatments prescribed by a medical expert. In our study it is a Psychiatrist. This result is also found in several international studies [24] [31].

\section{Conclusion}

Our study shows that the relationship between socio-economic factors such as "sex, age, origin, household size, rank among siblings, parents, marital status, educational level, occupation, and income," and the take of psychotropic medicines was much stronger in Morocco. However, to reduce the higher consumption of antidepressants, antipsychotics, anxiolytics and hypnotics, we must solve the socio-economic problems, which are responsible for the cause of psychic disorders within Moroccan population.

\section{Acknowledgements}

All the authors of this research would thank the Delegation of Health in Kenitra city, Ministry of Health, and all the staff of Moulay Al Hassan Hospital for their 
great help in the realization of this study. Also, they would thank all the patients and their families for their participation to this study.

\section{References}

[1] Kalant, H. (1998) Opioid Analgesics and Antagonists. In: Kalant, H. and Roschlau, W.H.E., Eds., Principles of Medical Pharmacology, Oxford University Press, Oxford, 262-277.

[2] Belkacem, A., El Omari, F., Khadri, J.E., Paes, M. and Ktiouet, J.E. (2006) Profil de prescription des psychotropes dans un organisme de Sécurité sociale marocain. Encéphale, 32, 335-340.

[3] Ohayon, M.M. and Lader, M.H. (2002) Use of Psychotropic Medication in the General Population of France, Germany, Italy, and United Kingdom. Journal of Clinical Psychiatry, 63, 817-825. https://doi.org/10.4088/JCP.v63n0912

[4] Melchior, M., Chastang, J.F., Leclerc, A., Ribet, C. and Rouillon, F. (2010) Low Socioeconomic Position and Depression Persistence: Longitudinal Results from the GAZEL Cohort Study. Psychiatry Research, 177, 92-96.

[5] Lecadet, J., Vidal, P., Baris, B., et al. (2003) Médicaments psychotropes: Consommation et pratiques de prescription en France métropolitaine. I. Données nationales, 2000. Rev Med Ass Maladie, 34, 75-83.

[6] Olié, J.P., El Omari, F., Spadone, C., et al. (2002) Résultat d'une enquête sur l'usage des antidépresseurs en population générale française. Encephale, 28, 411-417.

[7] Kisly, S., Linden, M., Bellantuono, C., et al. (2000) Why Are Patients Prescribed Psychotropic Drugs by General Practitioners, Results of International Study. Psychological Medicine, 30, 1217-1225. https://doi.org/10.1017/S0033291799002743

[8] Klemenc-Ketis, Z., Hladnik, Z. and Kersnik, J. (2011) A Cross Sectional Study of Sex Differences in Self-Medication Practices among University Students in Slovenia. Collegium Antropologicum, 35, 329-334.

[9] Dimatteo, M.R., Lepper, H.S. and Croghan, T.W. (2000) Depression Is a Risk Factor for Non-Compliance with Medical Treatment: Meta-Analysis of the Effects of Anxiety and Depression on Patient Adherence. Archives of Internal Medicine, 160, 2101-2107. https://doi.org/10.1001/archinte.160.14.2101

[10] Druss, B.G., Hoff, R.A. and Rosenheck, R.A. (2000) Underuse of Antidepressants in Major Depression: Prevalence and Correlates in a National Sample of Young Adults. Journal of Clinical Psychiatry, 61, 234-239. https://doi.org/10.4088/JCP.v61n0315

[11] Lagnaoui, R., Depont, F., Fourrier, A., et al. (2004) Patterns and Correlates of Benzodiazepine Use in the French General Population. European Journal of Clinical Pharmacology, 60, 523-529. https://doi.org/10.1007/s00228-004-0808-2

[12] Laukkala, T., Isometsa, E. and Hamalainen, J. (2001) Antidepressant Treatment of Depression in the Finnish General Population. American Journal of Psychiatry, 158, 2077-2079. https://doi.org/10.1176/appi.ajp.158.12.2077

[13] Lawrenson, R.A., Tyrer, F., Mewson, R.B., et al. (2000) The Treatment of Depression in UK General Practice: Selective in Reuptake Inhibitors and Tricyclic Antidepressants Compared. Journal of Affective Disorders, 59, 149-157. https://doi.org/10.1016/S0165-0327(99)00147-0

[14] Mueser, K.T. and Mcgurk, S.R. (2004) Schizophrenia. The Lancet, 363, 2063-2072. https://doi.org/10.1016/S0140-6736(04)16458-1

[15] Gasquet, I., Nègre-pagès, L., Fourrier, A., Nachbaur, G., El-hasnaoui, A., Kovess, V. 
and Lépine, J.P. (2005) Usage des psychotropes et troubles psychiatriques en France: Résultats de l'étude épidémiologique ESEMeD/MHEDEA 2000/(ESEMeD) en population générale. L'Encéphale, 31, 195-206.

https://doi.org/10.1016/S0013-7006(05)82386-3

[16] Bret, P., Bret, M.C. and Queuille, E. (2009) Prescribing Patterns of Antipsychotics in 13 French Psychiatric Hospitals. L'Encéphale, 35, 129-138. https://doi.org/10.1016/j.encep.2008.03.007

[17] Galland, O. (2000) Entrer dans la vie adulte: Des étapes toujours plus tardives, mais resserrées. Economie et Statistique, 337, 13-36. https://doi.org/10.3406/estat.2000.7494

[18] ESEMED/MHEDEA 2000/MHEDEA 2000 INVESTIGATORS (2004) Psychotropic Drug Utilization in Europe: Results from the European Study of the Epidemiology of Mental Disorders (ESEMeD/MHEDEA 2000) Project. Acta Psychiatrica Scandinavica, 109, 55-64.

[19] Kessler, R.C., Amminger, G.P., Aguilar-Gaxiola, S., Alonso, J., Lee, S. and Üstün, T.B. (2008) Age of Onset of Mental Disorders: A Review of Recent Literature. Current Opinion in Psychiatry, 20, 359-364. https://doi.org/10.1097/YCO.0b013e32816ebc8c

[20] Lépine, J.P., Gasquet, I., Kovess, V., et al. (2005) Prévalence et comorbidité des troubles psychiatriques dans la population générale française: Résultats de l'étude épidémiologique ESEMeD/MHEDEA 2000/(ESEMeD). L'Encéphale, 31, 182-194. https://doi.org/10.1016/S0013-7006(05)82385-1

[21] Cohen, D., Guilé, J.-M., Brunelle, J., Bodeau, N., Louët, E., Lucanto, R. and Consoli, A. (2009) Troubles bipolaires de type I de l'adolescent: Controverses et devenir à l'âge adulte. L'Encéphale, 35, 224-230. https://doi.org/10.1016/S0013-7006(09)73475-X

[22] Alonso, J., Angermeyer, M.C., Bernert, S., Bruffaerts, R., Brugha, T.S., Bryson, H., et al. (2004) Prevalence of Mental Disorders in Europe: Results from the European Study of the Epidemiology of Mental Disorders (ESEMeD) Project. Acta Psychiatrica Scandinavica, 109, 21-27.

[23] Khammassi, N., Ben Mansour, A., Abdelhedi, H. and Cherif, O. (2012) Les effets indésirables des psychotropes chez le sujet âgé: Étude rétrospective de 35 cas. Annales Médico-Psychologiques, Revue Psychiatrique, 170, 251-255. https://doi.org/10.1016/j.amp.2011.11.012

[24] De Monteynard, L.A., Younès, N. and Melchior, M. (2013) Facteurs sociodémographiques et recours aux soins pour raisons psychologiques chez les jeunes adultes. Revue d' Épidémiologie et de Santé Publiqu, 61, 351-361. https://doi.org/10.1016/j.respe.2013.03.047

[25] Melchior, M., Chastang, J.F., Head, J., Goldberg, M., Zins, M., Nabi, H., et al. (2013) Socioeconomic Position Predicts Long-Term Depression Trajectory: A 13-Year Follow-Up of the GAZEL Cohort Study. Molecular Psychiatry, 18, 112-121. https://doi.org/10.1038/mp.2011.116

[26] Dezetter, A., Briffault, X., Alonso, J., Angermeyer, M.C., Bruffaerts, R., De Girolamo, G., et al. (2011) Factors Associated with Use of Psychiatrists and Nonpsychiatrist Providers by ESEMeD Respondents in Six European Countries. Psychiatric Services, 62, 143-151. https://doi.org/10.1176/ps.62.2.pss6202_0143

[27] Meltzer, H., Bebbington, P., Dennis, M.S., Jenkins, R., McManus, S. and Brugha, T.S. (2013) Feelings of Loneliness among Adults with Mental Disorder. Social Psychiatry and Psychiatric Epidemiology, 48, 5-13. https://doi.org/10.1007/s00127-012-0515-8 
[28] Kessler, R.C., Berglund, P., Demler, O., Jin, R., Merikangas, K.R. and Walters, E.E. (2005) Lifetime Prevalence and Age-of-Onset Distributions of DSM-IV Disorders in the National Comorbidity Survey Replication. Archives of General Psychiatry, 62, 593-602. https://doi.org/10.1001/archpsyc.62.6.593

[29] Le Moigne, P. (2006) Dépendre de soi. L'usage au long cours des médicaments psychotropes. In: Collin, J., Otero, M. and Monnais, L, Eds., Le médicament au coeur de la socialité contemporaine: Regards croisées sur un sujet complexe, Presses Universitaires du Québec, Québec, 91-107.

[30] Amone, K., Burger, H., Huisman, M., Oldehinkel, A. and Ormel, J. (2011) Parental Psychopathology and Socioeconomic Position Predict Adolescent Offspring's Mental Health Independently and Do Not Interact: The TRAILS Study. Journal of Epidemiology and Community Health, 65, 57-63. https://doi.org/10.1136/jech.2009.092569

[31] Virtanen, M., Koskinen, S., Kivimäki, M., Honkonen, T., Vahtera, J., Ahola, K. and Lönnqvist, J. (2008) Contribution of Non-Work and Work-Related Risk Factors to the Association between Income and Mental Disorders in a Working Population: The Health 2000 Study. Occupational and Environmental Medicine, 65, 171-178. https://doi.org/10.1136/oem.2007.033159

Submit or recommend next manuscript to SCIRP and we will provide best service for you:

Accepting pre-submission inquiries through Email, Facebook, LinkedIn, Twitter, etc. A wide selection of journals (inclusive of 9 subjects, more than 200 journals)

Providing 24-hour high-quality service

User-friendly online submission system

Fair and swift peer-review system

Efficient typesetting and proofreading procedure

Display of the result of downloads and visits, as well as the number of cited articles

Maximum dissemination of your research work

Submit your manuscript at: http://papersubmission.scirp.org/

Or contact nm@scirp.org 